\title{
Species Distribution, Antifungal Susceptibility, and Molecular Epidemiology of Candida Species Causing Candidemia in a Tertiary Care Hospital in Bangkok, Thailand
}

\author{
Siriphan Boonsilp ${ }^{1, *(\mathbb{D})}$, Anchalee Homkaew ${ }^{2}$, Uraporn Phumisantiphong 1,2 (D), Daranee Nutalai ${ }^{2}$ (D) \\ and Thanwa Wongsuk $1, *$ (D) \\ 1 Department of Clinical Pathology, Faculty of Medicine Vajira Hospital, Navamindradhiraj University, \\ Bangkok 10300, Thailand; uraporn@nmu.ac.th \\ 2 Division of Central Laboratory and Blood Bank, Faculty of Medicine Vajira Hospital, \\ Navamindradhiraj University, Bangkok 10300, Thailand; anchalee.h@nmu.ac.th (A.H.); \\ daranee.nu@nmu.ac.th (D.N.) \\ * Correspondence: siriphan@nmu.ac.th (S.B.); thanwa@nmu.ac.th (T.W.)
}

\section{check for} updates

Citation: Boonsilp, S.; Homkaew, A.; Phumisantiphong, U.; Nutalai, D.; Wongsuk, T. Species Distribution, Antifungal Susceptibility, and Molecular Epidemiology of Candida Species Causing Candidemia in a Tertiary Care Hospital in Bangkok, Thailand. J. Fungi 2021, 7, 577. https://doi.org/10.3390/jof7070577

Academic Editor: Sofia

Costa-de-Oliveira

Received: 20 June 2021

Accepted: 15 July 2021

Published: 19 July 2021

Publisher's Note: MDPI stays neutral with regard to jurisdictional claims in published maps and institutional affiliations.

Copyright: (c) 2021 by the authors. Licensee MDPI, Basel, Switzerland. This article is an open access article distributed under the terms and conditions of the Creative Commons Attribution (CC BY) license (https:// creativecommons.org/licenses/by/ $4.0 /)$.

\begin{abstract}
Candida species represent a common cause of bloodstream infection (BSI). Given the emergence of non-albicans Candida (NAC) associated with treatment failure, investigations into the species distribution, fungal susceptibility profile, and molecular epidemiology of pathogens are necessary to optimize the treatment of candidemia and explore the transmission of drug resistance for control management. This study evaluated the prevalence, antifungal susceptibility, and molecular characteristics of Candida species causing BSI in a tertiary-level hospital in Bangkok, Thailand. In total, 54 Candida isolates were recovered from 49 patients with candidemia. C. tropicalis was the most prevalent species (33.3\%), followed by C. albicans (29.6\%). Most Candida species were susceptible to various antifungal agents, excluding C. glabrata and C. tropicalis, which had increased rates of nonsusceptibility to azoles. Most C. glabrata isolates were non-susceptible to echinocandins, especially caspofungin. The population structure of $C$. albicans was highly diverse, with clade 17 predominance. GoeBURST analysis of $C$. tropicalis revealed associations between genotype and fluconazole resistance in a particular clonal complex. The population structure of C. glabrata appeared to have a low level of genetic diversity in MLST loci. Collectively, these data might provide a fundamental database contributing to the development of novel antifungal agents and diagnostic tests.
\end{abstract}

Keywords: Candida; genotyping; susceptibility testing; goeBURST; multilocus sequence typing

\section{Introduction}

Candida species are important components of the microflora of the human skin, oral and vaginal mucosa, and gastrointestinal tract. They cause mild superficial and serious infections in humans [1]. Candida species represent the fourth most common cause of bloodstream infection (BSI) [2,3]. The incidence of BSI by Candida species has increased significantly over the past decade, and Candida has become an important cause of nosocomial infections. The risk factors for Candida BSI include long-term intensive care unit (ICU) hospitalization, central venous catheterization, organ transplantation, recent broadspectrum antibiotic use, and immunodeficiency [4]. Virulence factors such as germ tube formation, adhesins, phenotypic switching, biofilm formation, and hydrolytic enzyme production contribute to the pathogenesis of candidiasis [5]. Although C. albicans is the main global cause of BSI, non-albicans Candida (NAC) species are of increasing concern in patients with hematological conditions, those who underwent organ transplantation, and those admitted to an ICU [6]. The emergence of NAC is a serious issue because NAC species often display intrinsic and/or acquired resistance to commonly used antifungal drugs [6,7]. Different NAC species exhibit varying levels of virulence factors and resistance 
to antifungal drugs. The species distribution and drug resistance rate of Candida species vary between and within geographical regions; therefore, information on the species distribution, fungal susceptibility profile, and molecular epidemiology of NAC is necessary to optimize the treatment of candidemia and explore the transmission of drug resistance for control management. The multilocus sequence typing (MLST) technique is a widely used molecular typing method in molecular epidemiology for pathogenic Candida species including C. albicans, C. tropicalis, and C. glabrata. This method is based on the analysis of single-nucleotide polymorphisms in housekeeping gene fragments. The strain databases of different laboratories and different geographical regions can be compared through the online MLST database. This method provides insights into different geographical sources, anatomical sources, drug resistance acquisition transmission, and genetic variation patterns.

In this study, we examined the prevalence and MLST genotype data of Candida isolates recovered from patients with BSI at a tertiary care hospital in Bangkok, Thailand, in 2018 and 2019. Antifungal susceptibilities and genetic diversity are also reported. The relationship between susceptibility to azoles and diploid sequence types (DSTs) was also explored.

\section{Materials and Methods}

\subsection{Yeast Isolates, Identification, and Ethical Statement}

In total, 151 blood samples from 49 patients were cultured between June 2018 and July 2019 at the Department of Central Laboratory and Blood Bank, Faculty of Medicine, Vajira Hospital, Navamindradhiraj University (Bangkok, Thailand). Blood samples were incubated using the BACTEC 9240 system (Becton Dickinson, Le Pont de Claix, France). All isolates were identified using matrix-assisted laser desorption/ionization time-of-flight mass spectrometry (Bruker Microflex, Bremen, Germany). All Candida-positive blood cultures were incubated overnight on Sabouraud dextrose agar at $37^{\circ} \mathrm{C}$. Yeast species identification was confirmed using the sequence of the internal transcribed spacer sequence (ITS). Amplification and sequencing of the ITS region were performed using the primers ITS5 and ITS4 (Table S1) [8]. This work was approved by The Ethics Committee of the Faculty of Medicine Vajira Hospital, Navamindradhiraj University (COA 61/2561).

\subsection{Antifungal Susceptibility Testing}

Forty-one yeast isolates were available for antifungal susceptibility testing, which was performed using a colorimetric microdilution panel (SENSITITRE YeastOne Trek Diagnostic Systems, Cleveland, OH, USA) containing serial 2-fold dilutions of anidulafungin $(0.015-8 \mu \mathrm{g} / \mathrm{mL})$, micafungin $(0.008-8 \mu \mathrm{g} / \mathrm{mL})$, caspofungin $(0.008-8 \mu \mathrm{g} / \mathrm{mL}), 5$-flucytosine $(0.06-64 \mu \mathrm{g} / \mathrm{mL})$, posaconazole $(0.008-8 \mu \mathrm{g} / \mathrm{mL})$, voriconazole $(0.008-8 \mu \mathrm{g} / \mathrm{mL})$, itraconazole $(0.015-16 \mu \mathrm{g} / \mathrm{mL})$, fluconazole $(0.12-256 \mu \mathrm{g} / \mathrm{mL})$, and amphotericin B $(0.12-8 \mu \mathrm{g} / \mathrm{mL})$. Antifungal susceptibility testing was performed according to the manufacturer's recommendations. C. parapsilosis ATCC 22019 and C. krusei ATCC 6258 were used as reference strains for quality control. Minimum inhibitory concentrations (MICs) were measured after $24 \mathrm{~h}$ of incubation at $37^{\circ} \mathrm{C}$. Yeast growth was evidenced by a color change from blue (negative, indicating no growth) to red (positive, indicating growth).

\subsection{DNA Extraction}

Genomic DNA was extracted using 10\% Chelex solution in $0.1 \%$ Triton X-100 and $10 \mathrm{mM}$ Tris buffer ( $\mathrm{pH}$ 8.0). Then, $200 \mu \mathrm{L}$ of $10 \%$ Chelex solution was added to each yeast cell pellet. The mixture was vortexed for $10 \mathrm{~s}$, heated at $95^{\circ} \mathrm{C}$ for $20 \mathrm{~min}$, and centrifuged at $10,000 \times g$ for $20 \mathrm{~s}$. The supernatant was used as the substrate for PCR. 


\subsection{Genotyping}

Yeast isolates were genotyped via MLST. Three Candida MLST schemes published for C. albicans [9], C. tropicalis [10], and C. glabrata [11] were used to design the allelic profiles and sequence types (STs). Seven gene fragments were used for C. albicans: $A A T 1 a$, ACC1, ADP1, PMI1b, SYA1, VS13, and ZWF1a. The markers used for C. tropicalis were ICL1, MDR1, SAPT2, SAPT4, XYR1, and ZWF1a [10], and FKS, LEU2, NMT1, TRP1, UGP1, and URA3 were used for C. glabrata [11]. The gene fragments were amplified by PCR using primers from standardized MLST schemes. PCR was performed using Go Taq ${ }^{\circledR}$ Green Master Mix (Promega, Madison, WI, USA) in accordance with the manufacturer's instructions. The primers used for amplification of a fragment gene are listed in Table S1. PCR was performed in a reaction volume of $50 \mu \mathrm{L}$ under the following conditions: initial denaturation at $95^{\circ} \mathrm{C}$ for $5 \mathrm{~min}$; 35 cycles of denaturation $\left(95^{\circ} \mathrm{C}\right.$ for $\left.30 \mathrm{~s}\right)$, annealing $\left(50-60{ }^{\circ} \mathrm{C}\right.$ for $\left.30 \mathrm{~s}\right)$, and extension $\left(72{ }^{\circ} \mathrm{C}\right.$ for $\left.1 \mathrm{~min}\right)$; and a final extension step at $72{ }^{\circ} \mathrm{C}$ for $5 \mathrm{~min}$. All DNA fragments were sequenced in both directions using amplification primers from Macrogen Inc. DNASTAR Lasergene was used to align and edit DNA sequences. Heterozygosity was identified by the presence of two peaks at the same locus on both strands, and degenerated base sequences were recorded according to International Union of Pure and Applied Chemistry recommendations. The consensus sequences of seven loci were determined for all isolates. The consensus sequences of each locus of all isolates were submitted to the MLST database to define the allele profile and DST. The alignment and phylogenetic tree of the sequence data were adjusted manually for each gene using MEGA-X. Population structures were analyzed by the goeBURST algorithm using PHYLOViZ software.

\section{Results}

\subsection{Candida Species Distribution among Patients with Candidemia}

Candida species were recovered from all samples collected during the study period. The patient cohort included 29 male (59.18\%) and 20 female patients (40.82\%). The mean and median patient ages were 57.87 and 66 years, respectively (range, $0.03-99$ years). The mortality rate of the study cohort was $53.06 \%$. In total, 54 isolates were recovered from the patients. The most commonly isolated Candida species was C. tropicalis (33.33\%), followed by C. albicans $(29.63 \%)$, C. glabrata $(22.22 \%)$, C. parapsilosis $(9.26 \%)$, C. nivariensis $(1.85 \%)$, C. guilliermondii $(1.85 \%)$, and C. caribbica $(1.85 \%)$. C. tropicalis was the most common Candida isolate recovered from blood samples (Table 1). Five patients had mixed Candida infection, including coinfection with C. tropicalis and C. glabrata in two patients, C. albicans and C. glabrata in one patient, C. tropicalis and C. albicans in one patient, and C. tropicalis and C. parapsilosis in one patient.

C. tropicalis was associated with the highest mortality rate $(61.11 \%)$, followed by C. albicans $(56.25 \%)$, C. parapsilosis $(40 \%)$, and C. glabrata $(33.33 \%$, Table 2$)$. When analyzing Candida species in relation to patient age, we noticed that C. glabrata was the most common isolate among elderly patients, whereas C. parapsilosis was more common in younger patients. C. albicans and C. tropicalis were detected in all age groups (Figure 1). Regarding age-specific mortality, the highest mortality rate was recorded among patients aged $61-80$ years $(31.63 \%)$, followed by those aged $\geq 81$ years $(10.20 \%$ ). Patients younger than 60 years had lower mortality rates, including rates of 4.08 , 2.04 , and $4.98 \%$ among patients aged $0-20,20-40$, and $41-60$ years old, respectively (Figure S1). 
The distribution of Candida species isolates by hospital ward was determined. Among the 54 isolates, 38.89, 33.34, 12.96, 11.11, and 3.70\% were collected from patients in the surgery ward, internal medicine ward, pediatric/neonatal ICU, emergency room/emergency and medical ICU, and pediatric ward, respectively. C. albicans and C. tropicalis were found in patients admitted to all wards. C. albicans infection was more common in patients admitted to the surgery ward. C. tropicalis was a predominant species found in the internal medicine ward. C. glabrata was the most common species found in the emergency room/emergency and medical ICU, whereas C. parapsilosis was commonly found in the pediatric/neonatal ICU (Figure S2).

Table 1. Candida isolates among patients with positive hemoculture.

\begin{tabular}{cccc}
\hline Yeast Isolate & No. of Isolates (\%) & $\begin{array}{c}\text { Age } \\
\text { Mean } \pm \text { SD }\end{array}$ & \% Mortality \\
\hline Candida albicans & $16(29.63)$ & $58.77 \pm 24.37$ & 56.25 \\
Candida tropicalis & $18(33.33)$ & $63.90 \pm 24.53$ & 61.11 \\
Candida glabrata & $12(22.22)$ & $72 \pm 13.717$ & 33.33 \\
Candida parapsilosis & $5(9.26)$ & $26.23 \pm 36.76$ & 40 \\
Candida nivariensis & $1(1.85)$ & 54 & 0 \\
Candida guilliermondii & $1(1.85)$ & 0.03 & 0 \\
Candida caribbica & $1(1.85)$ & 59 & 0 \\
\hline
\end{tabular}

Table 2. Minimal inhibitory concentrations (MICs) of Candida species from blood as determined using The Clinical and Laboratory Standards Institute breakpoints.

\begin{tabular}{|c|c|c|c|c|c|c|c|c|c|c|}
\hline \multirow{2}{*}{ Candida Species } & \multirow{2}{*}{ Antifungal Agent } & \multicolumn{3}{|c|}{ MIC (ug/mL) } & \multicolumn{4}{|c|}{ Isolates (\%) } & \multicolumn{2}{|c|}{ Isolates (\%) } \\
\hline & & Range & $\mathrm{MIC}_{50}$ & $\mathrm{MIC}_{90}$ & $\mathbf{S}$ & SDD & I & $\mathbf{R}$ & wt & Non-wt \\
\hline \multirow{9}{*}{ C. albicans } & Anidulafungin & $0.015-0.12$ & 0.12 & 0.12 & 100 & $\mathrm{~N} / \mathrm{A}$ & 0 & 0 & 0 & 0 \\
\hline & Micafungin & $0.008-0.015$ & 0.008 & 0.015 & 100 & $\mathrm{~N} / \mathrm{A}$ & 0 & 0 & 0 & 0 \\
\hline & Caspofungin & $0.03-0.12$ & 0.12 & 0.12 & 100 & $\mathrm{~N} / \mathrm{A}$ & 0 & 0 & 0 & 0 \\
\hline & Flucyctosine & $0.06-0.12$ & 0.06 & 0.12 & $\mathrm{~N} / \mathrm{A}$ & $\mathrm{N} / \mathrm{A}$ & $\mathrm{N} / \mathrm{A}$ & $\mathrm{N} / \mathrm{A}$ & $\mathrm{N} / \mathrm{A}$ & $\mathrm{N} / \mathrm{A}$ \\
\hline & Posaconazole & 0.03 & 0.03 & 0.03 & $\mathrm{~N} / \mathrm{A}$ & $\mathrm{N} / \mathrm{A}$ & $\mathrm{N} / \mathrm{A}$ & $\mathrm{N} / \mathrm{A}$ & 100 & 0 \\
\hline & Voriconazole & $0.008-0.015$ & 0.008 & 0.015 & 100 & $\mathrm{~N} / \mathrm{A}$ & 0 & 0 & $\mathrm{~N} / \mathrm{A}$ & $\mathrm{N} / \mathrm{A}$ \\
\hline & Itaconazole & $0.06-0.25$ & 0.12 & 0.12 & $\mathrm{~N} / \mathrm{A}$ & $\mathrm{N} / \mathrm{A}$ & $\mathrm{N} / \mathrm{A}$ & $\mathrm{N} / \mathrm{A}$ & $\mathrm{N} / \mathrm{A}$ & $\mathrm{N} / \mathrm{A}$ \\
\hline & Fluconazole & $0.25-1$ & 0.5 & 1 & 100 & $\mathrm{~N} / \mathrm{A}$ & 0 & 0 & $\mathrm{~N} / \mathrm{A}$ & $\mathrm{N} / \mathrm{A}$ \\
\hline & AmphotericinB & $0.25-0.5$ & 0.5 & 0.5 & $\mathrm{~N} / \mathrm{A}$ & $\mathrm{N} / \mathrm{A}$ & $\mathrm{N} / \mathrm{A}$ & $\mathrm{N} / \mathrm{A}$ & 100 & 0 \\
\hline \multirow{9}{*}{ C. glabrata } & Anidulafungin & $0.03-0.25$ & 0.12 & 0.25 & 80 & $\mathrm{~N} / \mathrm{A}$ & 20 & 0 & $\mathrm{~N} / \mathrm{A}$ & $\mathrm{N} / \mathrm{A}$ \\
\hline & Micafungin & $0.15-0.03$ & 0.015 & 0.03 & 100 & $\mathrm{~N} / \mathrm{A}$ & 0 & 0 & $\mathrm{~N} / \mathrm{A}$ & $\mathrm{N} / \mathrm{A}$ \\
\hline & Caspofungin & $0.12-0.25$ & 0.25 & 0.25 & 20 & $\mathrm{~N} / \mathrm{A}$ & 80 & 0 & $\mathrm{~N} / \mathrm{A}$ & $\mathrm{N} / \mathrm{A}$ \\
\hline & Flucyctosine & $0.06-0.06$ & 0.06 & 0.06 & $\mathrm{~N} / \mathrm{A}$ & $\mathrm{N} / \mathrm{A}$ & $\mathrm{N} / \mathrm{A}$ & $\mathrm{N} / \mathrm{A}$ & $\mathrm{N} / \mathrm{A}$ & $\mathrm{N} / \mathrm{A}$ \\
\hline & Posaconazole & $1.0-2.0$ & 2.0 & 2 & $\mathrm{~N} / \mathrm{A}$ & $\mathrm{N} / \mathrm{A}$ & $\mathrm{N} / \mathrm{A}$ & $\mathrm{N} / \mathrm{A}$ & 10 & 90 \\
\hline & Voriconazole & $0.25-2$ & 1 & 2 & $\mathrm{~N} / \mathrm{A}$ & $\mathrm{N} / \mathrm{A}$ & $\mathrm{N} / \mathrm{A}$ & $\mathrm{N} / \mathrm{A}$ & 10 & 90 \\
\hline & Itaconazole & $0.5-2$ & 1 & 2 & $\mathrm{~N} / \mathrm{A}$ & $\mathrm{N} / \mathrm{A}$ & $\mathrm{N} / \mathrm{A}$ & $\mathrm{N} / \mathrm{A}$ & 100 & 0 \\
\hline & Fluconazole & $8-64$ & 32 & 64 & $\mathrm{~N} / \mathrm{A}$ & 80 & $\mathrm{~N} / \mathrm{A}$ & 20 & $\mathrm{~N} / \mathrm{A}$ & $\mathrm{N} / \mathrm{A}$ \\
\hline & AmphotericinB & $0.5-1$ & 0.5 & 1.0 & $\mathrm{~N} / \mathrm{A}$ & $\mathrm{N} / \mathrm{A}$ & $\mathrm{N} / \mathrm{A}$ & $\mathrm{N} / \mathrm{A}$ & 100 & 0 \\
\hline \multirow{8}{*}{ C. tropicalis } & Anidulafungin & $0.12-0.25$ & 0.12 & 0.12 & 100 & $\mathrm{~N} / \mathrm{A}$ & 0 & 0 & $\mathrm{~N} / \mathrm{A}$ & $\mathrm{N} / \mathrm{A}$ \\
\hline & Micafungin & $0.03-0.06$ & 0.03 & 0.03 & 100 & $\mathrm{~N} / \mathrm{A}$ & 0 & 0 & $\mathrm{~N} / \mathrm{A}$ & $\mathrm{N} / \mathrm{A}$ \\
\hline & Caspofungin & $0.06-0.25$ & 0.12 & 0.25 & 100 & $\mathrm{~N} / \mathrm{A}$ & 0 & 0 & $\mathrm{~N} / \mathrm{A}$ & $\mathrm{N} / \mathrm{A}$ \\
\hline & Flucyctosine & $0.06-0.12$ & 0.06 & 0.06 & $\mathrm{~N} / \mathrm{A}$ & $\mathrm{N} / \mathrm{A}$ & $\mathrm{N} / \mathrm{A}$ & $\mathrm{N} / \mathrm{A}$ & $\mathrm{N} / \mathrm{A}$ & $\mathrm{N} / \mathrm{A}$ \\
\hline & Posaconazole & $0.12-2$ & 0.25 & 2 & $\mathrm{~N} / \mathrm{A}$ & $\mathrm{N} / \mathrm{A}$ & $\mathrm{N} / \mathrm{A}$ & $\mathrm{N} / \mathrm{A}$ & 14.29 & 85.71 \\
\hline & Voriconazole & $0.12-8$ & 0.12 & 8 & 57.14 & $\mathrm{~N} / \mathrm{A}$ & 14.29 & 28.5 & $\mathrm{~N} / \mathrm{A}$ & $\mathrm{N} / \mathrm{A}$ \\
\hline & Itaconazole & $0.25-4$ & 0.25 & 2 & $\mathrm{~N} / \mathrm{A}$ & $\mathrm{N} / \mathrm{A}$ & $\mathrm{N} / \mathrm{A}$ & $\mathrm{N} / \mathrm{A}$ & 71.43 & 28.57 \\
\hline & Fluconazole & $2-256$ & 2 & 256 & 64.29 & $\mathrm{~N} / \mathrm{A}$ & 7.14 & 28.57 & $\mathrm{~N} / \mathrm{A}$ & $\mathrm{N} / \mathrm{A}$ \\
\hline \multirow{10}{*}{ C. parapsilosis } & AmphotericinB & $0.5-1$ & 1 & 1 & $\mathrm{~N} / \mathrm{A}$ & $\mathrm{N} / \mathrm{A}$ & $\mathrm{N} / \mathrm{A}$ & $\mathrm{N} / \mathrm{A}$ & 100 & 0 \\
\hline & Anidulafungin & $1-2$ & 1 & 2 & 100 & $\mathrm{~N} / \mathrm{A}$ & 0 & 0 & $\mathrm{~N} / \mathrm{A}$ & $\mathrm{N} / \mathrm{A}$ \\
\hline & Micafungin & $1-2$ & 1 & 2 & 100 & $\mathrm{~N} / \mathrm{A}$ & 0 & 0 & $\mathrm{~N} / \mathrm{A}$ & $\mathrm{N} / \mathrm{A}$ \\
\hline & Caspofungin & 0.5 & 0.5 & 0.5 & 100 & $\mathrm{~N} / \mathrm{A}$ & 0 & 0 & $\mathrm{~N} / \mathrm{A}$ & $\mathrm{N} / \mathrm{A}$ \\
\hline & Flucyctosine & $0.06-0.12$ & 0.12 & 0.12 & $\mathrm{~N} / \mathrm{A}$ & $\mathrm{N} / \mathrm{A}$ & $\mathrm{N} / \mathrm{A}$ & $\mathrm{N} / \mathrm{A}$ & $\mathrm{N} / \mathrm{A}$ & $\mathrm{N} / \mathrm{A}$ \\
\hline & Posaconazole & $0.03-0.12$ & 0.06 & 0.12 & $\mathrm{~N} / \mathrm{A}$ & $\mathrm{N} / \mathrm{A}$ & $\mathrm{N} / \mathrm{A}$ & $\mathrm{N} / \mathrm{A}$ & 100 & 0 \\
\hline & Voriconazole & $0.015-0.06$ & 0.015 & 0.12 & 100 & $\mathrm{~N} / \mathrm{A}$ & 0 & 0 & $\mathrm{~N} / \mathrm{A}$ & $\mathrm{N} / \mathrm{A}$ \\
\hline & Itaconazole & $0.06-0.25$ & 0.06 & 0.25 & $\mathrm{~N} / \mathrm{A}$ & $\mathrm{N} / \mathrm{A}$ & $\mathrm{N} / \mathrm{A}$ & $\mathrm{N} / \mathrm{A}$ & $\mathrm{N} / \mathrm{A}$ & $\mathrm{N} / \mathrm{A}$ \\
\hline & Fluconazole & $0.5-4$ & 1 & 2 & 50 & $\mathrm{~N} / \mathrm{A}$ & 50 & 0 & $\mathrm{~N} / \mathrm{A}$ & $\mathrm{N} / \mathrm{A}$ \\
\hline & AmphotericinB & 0.5 & 0.5 & 0.5 & $\mathrm{~N} / \mathrm{A}$ & $\mathrm{N} / \mathrm{A}$ & $\mathrm{N} / \mathrm{A}$ & $\mathrm{N} / \mathrm{A}$ & 100 & 0 \\
\hline
\end{tabular}




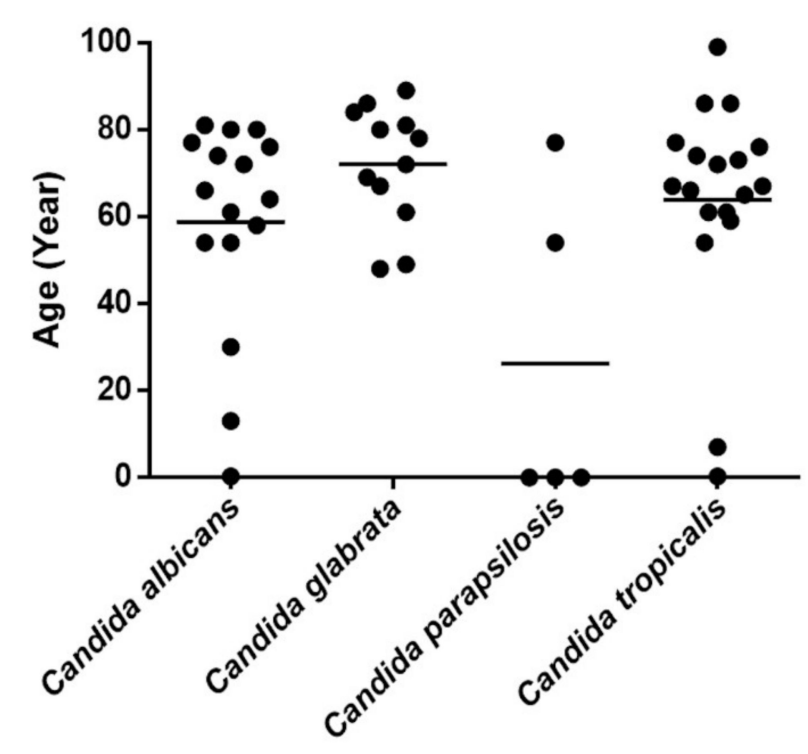

Figure 1. Candida species distribution by patient age (years).

\subsection{Antifungal Susceptibility Testing}

Antifungal susceptibility was tested in 41 Candida isolates from patients with candidemia using interpretative breakpoints defined by The Clinical and Laboratory Standards Institute. The susceptibility rates of Candida against nine antifungal agents are presented in Table 2. C. albicans and C. parapsilosis were susceptible (wild-type) to all antifungal drugs tested, excluding intermediate susceptibility (50\%) to fluconazole in C. parapsilosis. The rates of susceptibility to fluconazole were $80,64.29$, and $50 \%$ in C. glabrata, C. tropicalis, and C. parapsilosis, respectively. In total, $28.57 \%$ of $C$. tropicalis isolates and $20 \%$ of $C$. glabrata isolates were resistant to fluconazole. All fluconazole-resistant isolates of $C$. tropicalis and C. glabrata were cross-resistant to voriconazole and posaconazole. All C. tropicalis isolates were susceptible to echinocandins (anidulafungin, micafungin, and caspofungin). All C. glabrata isolates were susceptible to micafungin, whereas $20 \%$ and $80 \%$ of C. glabrata isolates had reduced susceptibility to anidulafungin and caspofungin, respectively. Applying the epidemiological cutoff value, all isolates in this study were susceptible to amphotericin $B$ and 5 -flucytosine. The non-wild-type phenotype rates regarding posaconazole susceptibility were $85.71 \%$ for C. tropicalis, and $90 \%$ for C. glabrata. Meanwhile, $28.57 \%$ of C. tropicalis isolates had a non-wild-type phenotype for itraconazole, whereas $C$. glabrata isolates were susceptible to itraconazole. Cross-resistance to voriconazole and posaconazole was observed in $20 \%$ of fluconazole-resistant C. glabrata isolates. Cross-resistance to voriconazole, itraconazole, and posaconazole was observed in $28.57 \%$ of fluconazole-resistant $C$. tropicalis isolates. C. guilliermondii was susceptible to micafungin and caspofungin, but it displayed reduced susceptibility to anidulafungin and posaconazole. C. caribbica exhibited a high MIC for fluconazole $(8 \mu \mathrm{g} / \mathrm{mL})$.

\subsection{MLST of C. tropicalis}

In total, 14 C. tropicalis strains isolated from 14 patients were subjected to MLST. Concatenation of six housekeeping genes obtained a dataset of $2677 \mathrm{bp}$ for each isolate, and $12(0.45 \%)$ polymorphic sites were evaluated. The highest number of variable sites was identified for MDR1 (5,1.18\%), whereas no polymorphic sites were found for XYR1 among the study isolates. The 14 isolates were classified into 12 distinct DSTs. Among these, 3 DSTs (DST506, DST667, and DST889) obtained from 4 strains belonged to previously described MLST genotypes, whereas 9 DSTs (DST1097-DST1105) obtained from 10 strains were new genotypes that were added to the $C$. tropicalis MLST central database. 
Using the goeBURST algorithm, the allelic profiles of these isolates were compared with those of 1263 isolates in the MLST database. Four clonal complexes (CC1, CC12, CC56, and CC111) and five singletons containing the DSTs found in this study are illustrated in Figure 2A. All strains of fluconazole-resistant C. tropicalis belonging to three DSTs (DST506, DST 1101, and DST1097) were grouped in cluster CC1. The other 10 isolates were susceptible to fluconazole, and they were scattered among CC12 (DST667 and DST 1105), CC56 (DST 1100), CC111 (DST 1103), and singletons (DST889, DST1102, DST1104, DST1098, and DST1099).

The genetic relationship among the DSTs of $C$. tropicalis isolates in this study was evaluated by constructing an unrooted dendrogram based on MLST data. The unweighted pair group method with arithmetic mean (UPGMA) dendrogram revealed that the 14 isolates belonged to four groups and five singletons. CC1 was the most common cluster type $(28.6 \%)$, and it was the only fluconazole- and voriconazole-resistant cluster in this study (Figure 2B).

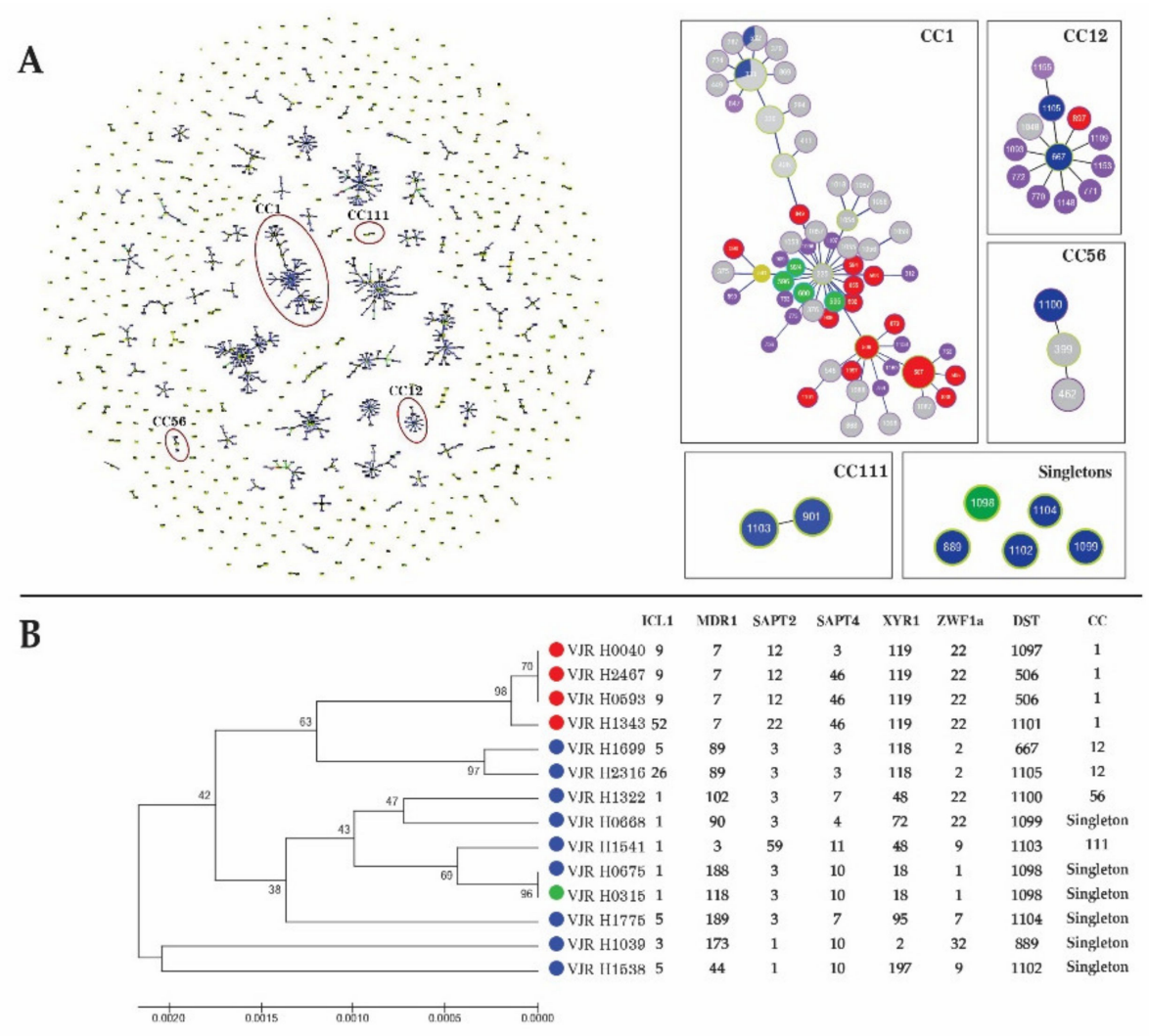

Figure 2. (A) Genetic population structure of 1263 Candida tropicalis isolates. Population snapshot obtained by goeBURST analysis using the 1161 diploid sequence types (DSTs), which were linked when they had differences in one of the six loci used for multilocus sequence typing (MLST). Single DSTs represent singletons. Clonal complex 1 (CC1; DST506, DST1097, and DST 1101), CC12 (DST667 and DST 1105), CC56 (DST 1100), and CC111 (DST 1103) contain DSTs from this study. DST889, DST1102, DST1104, DST1098, and DST1099 are singletons from this study. The size of each DST reflects the number of associated strains. (B) Dendrogram generated from MLST data for 14 C. tropicalis isolates from patients with bloodstream infection. Phylogenetic analysis was performed using the unweighted pair group method with arithmetic mean (UPGMA). Strains are classified as fluconazole-susceptible (blue), intermediate (green), and fluconazole-resistant (red). The CCs determined by goeBURST were generally consistent with the groups defined by UPGMA. 


\subsection{MLST of C. albicans}

Ten C. albicans isolates from patients with candidemia were subjected to genotyping using the $C$. albicans MLST scheme. The DNA sequences of the fragments of seven different housekeeping genes were concatenated to generate a dataset of $2883 \mathrm{bp}$ for each isolate. MLST revealed that 25 nucleotide sites $(0.87 \%)$ were variable, and of these, the highest number $(n=9)$ of polymorphic sites was identified for ADP1. Conversely, ACC1 had the lowest number of polymorphic sites $(n=2)$. The allelic diversity of the $10 \mathrm{C}$. albicans isolates regarding the seven loci included nine unique DSTs and one untypable strain. All nine unique DSTs represented novel strains, all of which were submitted to the $C$. albicans MLST scheme (DST3572-DST3580). One isolate was not typable because of two nucleotide insertions in the VPS13 fragment.

The goeBURST algorithm was used to analyze the genotype relationships in comparison with the available DSTs $(n=3637)$ in the MLST database. In total, 158 CCs and 1143 singleton strains were identified. Six isolates were placed in three CCs (CC3, CC25, and CC84), whereas three isolates were singletons. Three DSTs (DST3574, DST3575, and DST3579) were grouped in CC84. Two DSTs (DST3576 and DST3580) belonged to CC25. An isolate of DST3573 clustered into CC3. The other three isolates containing DST3572, DST3578, and DST3577 were unrelated singletons (Figure 3). Based on UPGMA, clades 17 $(55.6 \%), 1(22.2 \%), 8(11.1 \%)$, and $5(11.1 \%)$ were identified (Figure S3).

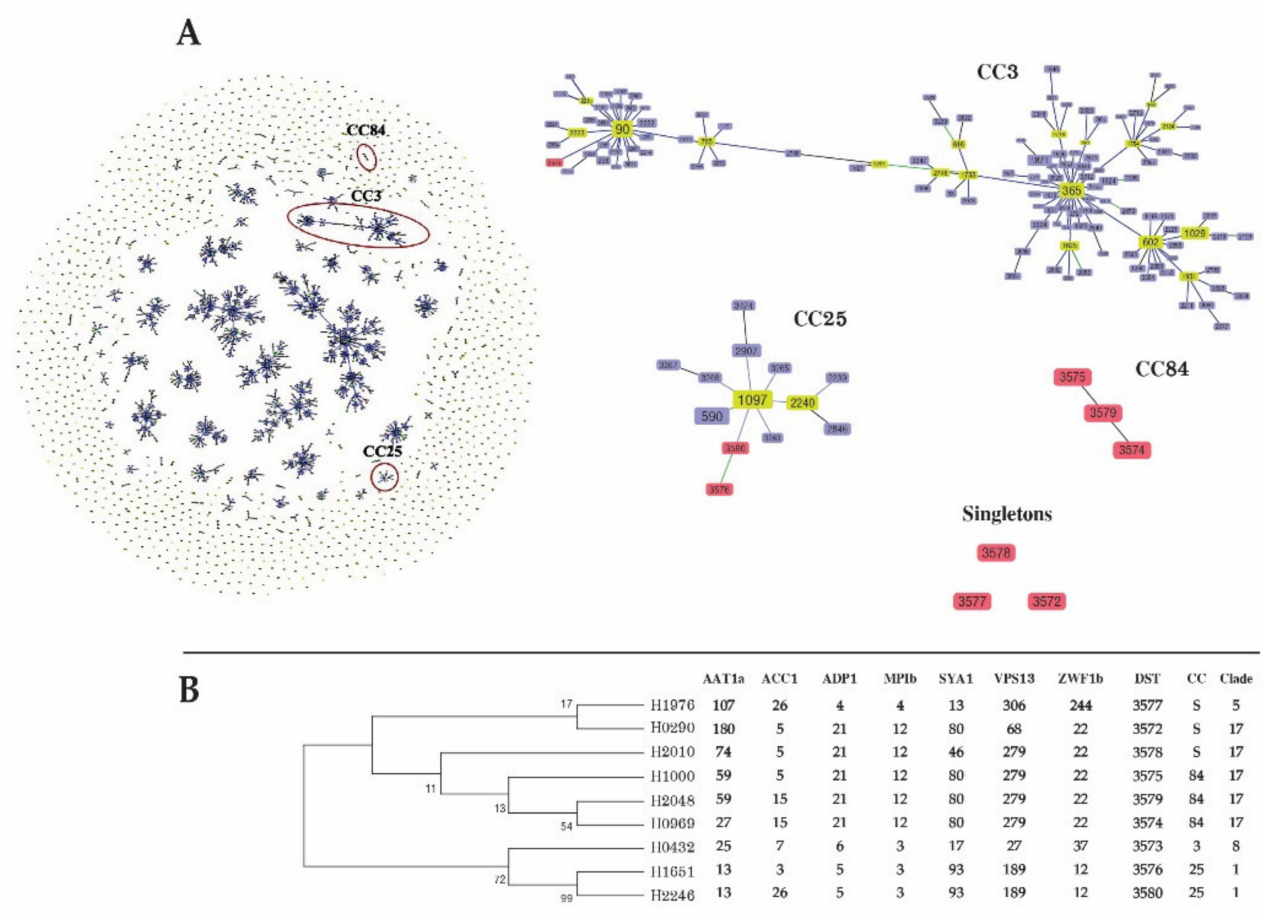

Figure 3. (A) goeBURST analysis of 4469 Candida albicans entries in the C. albicans multilocus sequence typing (MLST) database, which can be grouped into 3637 sequence types. Numbers in nodes represent diploid sequence types (DSTs), light green denotes founder groups, light yellow denotes subgroup founders, and red indicates DSTs identified in the present study. (B) Maximum likelihood tree of C. albicans based on a concatenated sequence of seven MLST loci among nine C. albicans isolates obtained from patients with bloodstream infection in this study.

\subsection{MLST of C. glabrata}

MLST of 10 C. glabrata isolates covered 3345 nucleotides and 31 (0.93\%) polymorphic sites. The NMT1 gene featured the highest number $(n=10)$ of polymorphic sites, whereas the URA3 gene carried the lowest number of sites $(n=2)$. The concatenated sequence of the 10 isolates was classified into 4 unique STs. Nine isolates belonged to three previously described STs (ST7, ST55, and ST195). Only one isolate belonged to a new ST (ST199). 
The data have been submitted to the $C$. glabrata MLST database. The most common DST was ST55 (60\%), followed by ST7 (20\%), ST195 (10\%), and ST199 $(10 \%)$.

The goeBURST algorithm was used to analyze the genetic relationships among the 10 C. glabrata isolates and 1377 isolates deposited in the C. glabrata MLST database. In total, 204 DSTs were grouped into 23 CCs and 53 singletons. All CCs containing DSTs identified in this study are presented in Figure 4. The most common genotype (ST55), which contained six isolates from this study, was grouped in CC13. Two ST7 isolates clustered into CC3. A genotype of ST199 belonged to CC3. DST195 could not be assigned to any known CC.

A

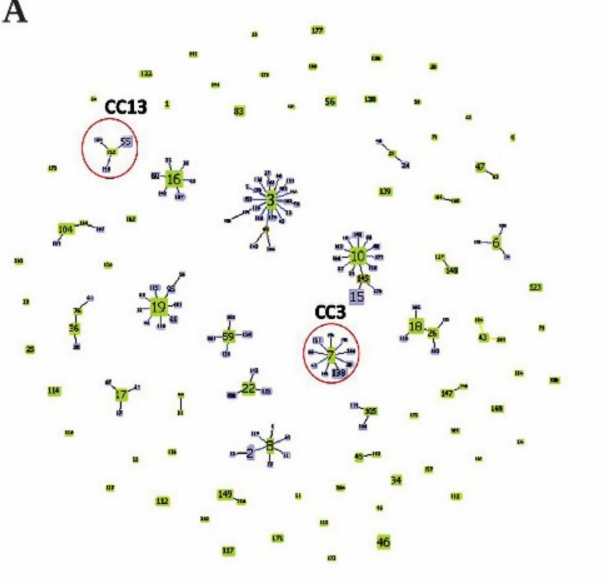

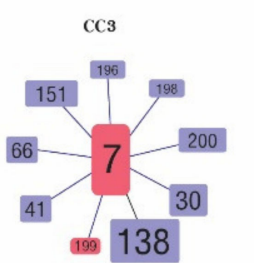
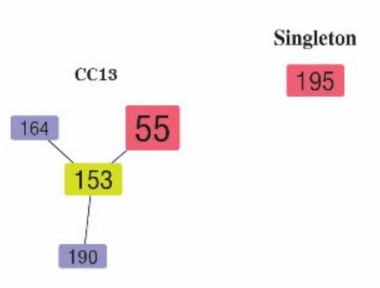

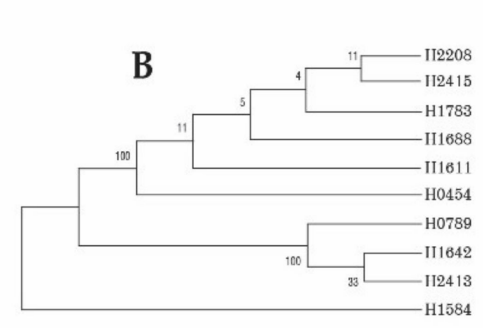

FKS
3
3
3
3
3
3
3
3
3
10

$\begin{array}{ccc}\text { LEU2 } & \text { NMT1 } & \text { TRP1 } \\ 6 & 22 & 2 \\ 6 & 22 & 2 \\ 6 & 22 & 2 \\ 6 & 22 & 2 \\ 6 & 22 & 2 \\ 6 & 22 & 2 \\ 4 & 4 & 3 \\ 4 & 62 & 3 \\ 4 & 4 & 3 \\ 21 & 10 & 4\end{array}$

$\begin{array}{ccc}\text { URA3 } & \text { sT } & \text { CC } \\ 9 & 55 & 13 \\ 9 & 55 & 13 \\ 9 & 55 & 13 \\ 9 & 55 & 13 \\ 9 & 55 & 13 \\ 9 & 55 & 13 \\ 4 & 7 & 3 \\ 4 & 199 & 3 \\ 4 & 7 & 3 \\ 9 & 195 & \mathrm{~S}\end{array}$

Figure 4. (A) goeBURST analysis of 1377 Candida glabrata entries in the C. glabrata multilocus sequence typing (MLST) database, which could be grouped into 204 sequence types (STs). Numbers in nodes represent STs, light green denotes founder groups, light yellow denotes subgroup founders, and red indicates diploid sequence types identified in the present study. (B) Maximum likelihood tree of C. glabrata based on the concatenated sequence of 6 MLST loci among 10 C. glabrata strains isolated from patients with bloodstream infection in this study.

\section{Discussion}

This study identified four different Candida species that cause BSI among patients hospitalized in our institution in 2018 and 2019. C. tropicalis was the most common cause of candidemia, followed by C. albicans, C. glabrata, and C. parapsilosis. This is consistent with previous studies, including a report that $C$. tropicalis was the most frequent species isolated from blood samples in the same geographic area of Thailand [12-15]. Although several studies identified C. albicans as the most common fungus isolated from blood samples, more recent studies reported a decreasing frequency of $C$. albicans-associated candidemia and an increasing frequency of candidemia associated with NAC [16-18]. Approximately $5.5 \%$ of all Candida isolates were uncommon species, such as C. nivariensis, C. guilliermondii, and C. caribbica. These rare yeasts have been reported as emerging causes of BSI [19-21].

The mortality rate of candidemia in our study was $53.6 \%$, which is comparable to that of previous reports $[14,17,22]$. The high rate of mortality among elderly patients is consistent with previous findings [23,24]. Moreover, C. tropicalis candidemia carried the highest risk of mortality in our study. In line with our findings, several previous studies also described that patients with $C$. tropicalis fungemia have a higher mortality rate than 
those infected by other Candida species $[25,26]$. Several virulence mechanisms of $C$. tropicalis have been proposed, such as adhesion, biofilm formation, dissemination, hyphae formation, and enzyme production [27]. Therefore, physicians should pay careful attention to patients with persistent candidemia caused by C. tropicalis. In the present study, C. glabrata was more commonly isolated from elderly patients. This finding is consistent with previous findings of $C$. glabrata as the most prevalent Candida species in elderly patients. The mean age of patients with C. glabrata-associated candidemia was $72 \pm 13.717$ years in our study, in line with prior findings $[28,29]$. This association may be related to earlier treatment with antifungal drugs or underlying diseases. A higher rate of oropharyngeal colonization by C. glabrata in older patients has been reported [30]. Patients with C. parapsilosis-associated candidemia tended to be younger, which may reflect the use of intravascular devices to treat neonates [31].

Several classes of antifungal drugs such as azoles, echinocandins, and polyenes are available for candidemia treatment. The local epidemiology is an important factor for selecting an antifungal drug. Knowledge of antifungal susceptibility patterns and resistance rates is helpful for patient management in each region, especially in settings with an emerging NAC predominance. In the present study, fluconazole was active against all C. albicans isolates, implying that fluconazole could be used as a first-line agent in patients infected by C. albicans. Fluconazole resistance was found in C. tropicalis and C. glabrata isolates, whereas some strains exhibited intermediate susceptibility to fluconazole. This is consistent with recent findings in Asia that fluconazole susceptibility was almost universal for C. albicans, whereas NAC strains that cause candidemia had reduced susceptibility $[15,32]$. In previous studies, low rates of amphotericin B resistance were reported in C. albicans, C. glabrata, C. parapsilosis, C. tropicalis, C. kefyr, and C. krusei isolates [33-35]. In our study, amphotericin $\mathrm{B}$ displayed excellent activity against all Candida species. Overall, itraconazole was extremely active against most Candida species, excluding C. tropicalis. Many studies reported that non-susceptibility to itraconazole was most common among C. glabrata isolates [36,37]. By contrast, no isolates with reduced itraconazole susceptibility were identified in this study. Posaconazole is known to be active against a variety of Candida species. In our study, all C. albicans and C. parapsilosis isolates were susceptible to posaconazole, but $90 \%$ of C. glabrata and $85.7 \%$ of $C$. tropicalis isolates exhibited diminished susceptibility. Resistance to voriconazole was observed in some $C$. tropicalis strains, and most C. glabrata isolates displayed reduced susceptibility to voriconazole. Cross-resistance to voriconazole and other azoles such as fluconazole, itraconazole, and posaconazole was also observed in this study. These findings are consistent with previous reports that $C$. glabrata and $C$. tropicalis display higher rates of azole resistance than other Candida clinical isolates and exhibit intrinsically lower susceptibility to the azole class [38-41]. Echinocandins such as micafungin, anidulafungin, and caspofungin represent the preferred choice of treatment for several forms of candidiasis. In our study, the in vitro activity of echinocandins against most Candida species was high, excluding C. glabrata. These data are consistent with previous results [42-44], and they document the excellent potency and spectrum of echinocandins against most Candida species other than C. glabrata, which has reduced susceptibility in some settings [45].

In line with its higher rate of fluconazole resistance, $C$. tropicalis was associated with the highest mortality rate. Based on its high prevalence and fluconazole resistance, $C$. tropicalis is a serious pathogen reducing the efficacy of fluconazole therapy. MLST can clarify the genetic diversity among isolates and characterize the fluconazole susceptibility pattern [46]. The genetic diversity observed in this study was comparable to that of a previous study in Thailand [12] but higher than that in other countries [47]. CC1, a major cluster associated with azole resistance in this study, is a large fluconazole-non-susceptible group found in Taiwan and China $[46,48]$. This suggests that CC1 reflects the clonal distribution of azole-resistant isolates across Asia. MLST is suitable for studying the epidemiology of fluconazole-susceptible and fluconazole-resistant $C$. tropicalis clusters. 
C. albicans is a common cause of candidemia globally. Similarly, C. albicans was the second most common cause of candidemia in this study. Globally, antibiotic resistance in C. albicans is extremely rare [32,49]. Correspondingly, C. albicans blood isolates in our study were highly susceptible to all antifungal agents. This suggests that antifungal agents remain effective in the treatment of $C$. albicans BSI. Globally C. albicans remains the most common cause of BSI. The propensity of $C$. albicans to cause infections is the result of genetic plasticity that allows it to adapt to changing or stressful environments. CC84, which was newly identified in this study, reflects the geographical association of genotype clustering in Thailand. The $C$. albicans strains isolated in this study exhibited extremely high genetic diversity. These data confirm previous observations of high genetic diversity among the STs of $C$. albicans $[50,51]$. This genetic plasticity may be explained by the heterozygosity of the diploid C. albicans genome, thereby contributing to a high rate of genetic exchange [52]. Host association is also reported to induce genetic variation in C. albicans, which affects virulence phenotypes [53]. Cluster analysis using MLST revealed some phenotypic characteristics that may have a geographic origin [54]. To date, 19 genetic clades have been reported using MLST. In general, clade 1 was most common among C. albicans strains causing BSI, whereas clade 17 was rare [50]. Conversely, our result indicates that clade 17 was the most common of the BSI C. albicans, whereas clade 1 was detected less frequently. Clade 17 is uncommon globally among C. albicans strains collected from blood samples. A previous study in Thailand reported a high prevalence of clade 17 among Thai patients with $C$. albicans BSI [55]. Clade 17 required stronger hemolytic activity for BSI [56]. This confirms the present observation of the high genetic diversity of clade 17, and its predominance in Thailand.

C. glabrata was the third most common cause of candidemia in this study, and it exhibited reduced susceptibility to azoles and echinocandins. Whereas ST55 was the predominant type in this study, a previous study found that ST7 was the major type associated with BSI in Japan, Korea, and China; contrarily, ST55 was uncommon [11,57-59]. The prevalence of circulating STs also displayed a geographical bias [60]. Hence, genetic variation among isolates in a particular region cannot be generalized to other areas. We found no association between drug resistance and ST. However, the number of isolates was too small to permit a reliable statistical analysis of isolates or conduct association analysis.

\section{Conclusions}

This study explored the species distribution, molecular epidemiology, and antifungal susceptibility profiles of Candida species causing candidemia in our hospital. C. tropicalis was the predominant species causing BSI, and strains of this species tended to rapidly acquire resistance to fluconazole. MLST and goeBURST analysis revealed an association between CCs and fluconazole resistance. C. albicans was the second most common pathogenic cause, and it was extremely sensitive to various antifungal agents. C. albicans strains exhibited high genetic diversity, which allowed them to adapt to new environment conditions. Clade 17 was the predominant $C$. albicans clade causing candidemia. It is possible that this clade possesses higher virulence traits than other isolates. C. glabrata exhibited reduced susceptibility to azoles and less genetic diversity. No association existed between drug resistance and ST among $C$. glabrata isolates. This study provides a picture of the molecular epidemiology and drug resistance rates of Candida species in Thailand. These data might be helpful for improving therapeutic management of patients with Candida infection and boosting the development of novel antifungal agents and diagnostic tests.

Supplementary Materials: Supplementary Materials (Figures S1-S3, Table S1) are available online at https:/ / www.mdpi.com/article/10.3390/jof7070577/s1. Figure S1. Mortality rate by age group among patients with candidemia. Figure S2. The composition of Candida species isolated from blood culture in different hospital units. Figure S3. A phylogram was constructed via the unweighted pair group method with arithmetic mean based on the concatenated sequence of seven loci of Candida albicans. Clades were assigned by comparing the sequences obtained in this study to the reference sequences. Table S1. Primer sequence and PCR condition. 
Author Contributions: Designed the study: S.B. and T.W.; performed antifungal susceptibility test and molecular identification and typing technique: S.B., T.W., and A.H.; performed yeast isolation, MALDI-TOF MS, and data collection: A.H., D.N., and U.P.; analyzed the data and wrote the manuscript: S.B. All authors have read and agreed to the published version of the manuscript.

Funding: This work was supported by the Navamindradhiraj University Research Fund (No. 35/2561), a grant from Navamindradhiraj University.

Institutional Review Board Statement: The Ethics Committee of the Faculty of Medicine Vajira Hospital, Navamindradhiraj University, Bangkok, Thailand (COA 61/2561) approved this study.

Informed Consent Statement: Not applicable.

Data Availability Statement: Sequence typing genotypes are available at PubMLST.org (on date 7 July 2021 for C. albicans MLST and 24 August 2021 for C. tropicalis MLST).

Acknowledgments: We sincerely appreciate the assistance of Marie-Elisabeth Bougnoux (C. albicans MLST database curator), Hsiu-Jung Lo (C. tropicalis MLST database curator), and Oliver Bader (C. glabrata MLST database curator) for their kind help in assigning new allele numbers and DSTs published in MLST databases.

Conflicts of Interest: The authors declare no conflict of interest in this article. The funders had no role in the design of the study; in the collection, analyses, or interpretation of data; in the writing of the manuscript, or in the decision to publish the results.

\section{References}

1. Brown, G.D.; Denning, D.W.; Gow, N.A.R.; Levitz, S.M.; Netea, M.G.; White, T.C. Hidden Killers: Human Fungal Infections. Sci. Transl. Med. 2012, 4, 165rv13. [CrossRef]

2. Méan, M.; Marchetti, O.; Calandra, T. Bench-to-bedside review: Candida infections in the intensive care unit. Crit. Care 2008, 12, 204. [CrossRef]

3. Wisplinghoff, H.; Bischoff, T.; Tallent, S.M.; Seifert, H.; Wenzel, R.P.; Edmond, M.B. Nosocomial Bloodstream Infections in US Hospitals: Analysis of 24,179 Cases from a Prospective Nationwide Surveillance Study. Clin. Infect. Dis. $2004,39,309-317$. [CrossRef]

4. Yapar, N. Epidemiology and risk factors for invasive candidiasis. Ther. Clin. Risk Manag. 2014, 10, 95-105. [CrossRef]

5. Sardi, J.C.O.; Scorzoni, L.; Bernardi, T.; Fusco-Almeida, A.M.; Mendes Giannini, M.J.S. Candida species: Current epidemiology, pathogenicity, biofilm formation, natural antifungal products and new therapeutic options. J. Med. Microbiol. 2013, 62 Pt 1, 10-24. [CrossRef]

6. $\quad$ Richter, S.S.; Galask, R.P.; Messer, S.A.; Hollis, R.J.; Diekema, D.; Pfaller, M.A. Antifungal Susceptibilities of Candida Species Causing Vulvovaginitis and Epidemiology of Recurrent Cases. J. Clin. Microbiol. 2005, 43, 2155-2162. [CrossRef]

7. Krcmery, V.; Barnes, A. Non-albicans Candida spp. causing fungaemia: Pathogenicity and antifungal resistance. J. Hosp. Infect. 2002, 50, 243-260. [CrossRef] [PubMed]

8. White, T.J.; Bruns, T.; Lee, S.; Taylor, J. Amplification and direct sequencing of fungal ribosomal RNA genes for phylogenetics. In PCR Protocols, a Guide to Methods and Applications; Innis, M.A., Gelfand, D.H., Sninsky, J.J., White, T.J., Eds.; Academic Press: San Diego, CA, USA, 1990; pp. 315-322.

9. Bougnoux, M.-E.; Tavanti, A.; Bouchier, C.; Gow, N.A.R.; Magnier, A.; Davidson, A.D.; Maiden, M.C.J.; D’Enfert, C.; Odds, F.C. Collaborative Consensus for Optimized Multilocus Sequence Typing of Candida albicans. J. Clin. Microbiol. 2003, 41, 5265-5266. [CrossRef]

10. Tavanti, A.; Davidson, A.D.; Johnson, E.M.; Maiden, M.C.J.; Shaw, D.J.; Gow, N.; Odds, F.C. Multilocus Sequence Typing for Differentiation of Strains of Candida tropicalis. J. Clin. Microbiol. 2005, 43, 5593-5600. [CrossRef]

11. Dodgson, A.R.; Pujol, C.; Denning, D.W.; Soll, D.R.; Fox, A.J. Multilocus sequence typing of Candida glabrata reveals geographically enriched clades. J. Clin. Microbiol. 2003, 41, 5709-5717. [CrossRef]

12. Tulyaprawat, O.; Pharkjaksu, S.; Chongtrakool, P.; Ngamskulrungroj, P. An Association of an eBURST Group with Triazole Resistance of Candida tropicalis Blood Isolates. Front. Microbiol. 2020, 11, 934. [CrossRef]

13. Chai, Y.A.; Wang, Y.; Khoo, A.L.; Chan, F.Y.; Chow, C.; Kumarasinghe, G.; Singh, K.; Tambyah, P.A. Predominance of Candida tropicalis bloodstream infections in a Singapore teaching hospital. Med. Mycol. 2007, 45, 435-439. [CrossRef]

14. Kang, S.J.; Kim, S.E.; Kim, U.J.; Jang, H.-C.; Park, K.-H.; Shin, J.H.; Jung, S.I. Clinical characteristics and risk factors for mortality in adult patients with persistent candidemia. J. Infect. 2017, 75, 246-253. [CrossRef]

15. NaRanong, C.; Anunnatsiri, S.; Srigulbutr, S. Epidemiology and Antifungal Susceptibility in Patients with Candidemia in a University Hospital, Thailand. J. Med. Assoc. Thai. 2020, 103, 1048-1056. [CrossRef]

16. Kothalawala, M.; Jayaweera, J.; Arunan, S.; Jayathilake, A. The emergence of non-albicans candidemia and evaluation of HiChrome Candida differential agar and VITEK2 YST(R) platform for differentiation of Candida bloodstream isolates in teaching hospital Kandy, Sri Lanka. BMC Microbiol. 2019, 19, 136. [CrossRef] 
17. Xiao, Z.; Wang, Q.; Zhu, F.; An, Y. Epidemiology, species distribution, antifungal susceptibility and mortality risk factors of candidemia among critically ill patients: A retrospective study from 2011 to 2017 in a teaching hospital in China. Antimicrob. Resist. Infect. Control 2019, 8, 89. [CrossRef]

18. Lamoth, F.; Lockhart, S.R.; Berkow, E.L.; Calandra, T. Changes in the epidemiological landscape of invasive candidiasis. J. Antimicrob. Chemother. 2018, 73, i4-i13. [CrossRef]

19. Morita, K.; Honda, A.; Koya, J.; Toyama, K.; Ikeda, M.; Misawa, Y.; Okugawa, S.; Nakamura, F.; Moriya, K.; Kurokawa, M. Three cases of Candida fermentati fungemia following hematopoietic stem cell transplantation. J. Infect. Chemother. 2018, 24, 576-578. [CrossRef] [PubMed]

20. Borman, A.M.; Petch, R.; Linton, C.J.; Palmer, M.; Bridge, P.D.; Johnson, E.M. Candida nivariensis, an Emerging Pathogenic Fungus with Multidrug Resistance to Antifungal Agents. J. Clin. Microbiol. 2008, 46, 933-938. [CrossRef]

21. Güler, N.C.; Tosun, I.; Aydin, F. The identification of Meyerozyma guilliermondii from blood cultures and surveillance samples in a university hospital in Northeast Turkey: A ten-year survey. J. Mycol. Méd. 2017, 27, 506-513. [CrossRef]

22. Kett, D.H.; Azoulay, E.; Echeverria, P.M.; Vincent, J.-L. Candida bloodstream infections in intensive care units: Analysis of the extended prevalence of infection in intensive care unit study. Crit. Care Med. 2011, 39, 665-670. [CrossRef]

23. Dimopoulos, G.; Flevari, A.; Theodorakopoulou, M.; Velegraki, A.; Armaganidis, A. Treatment of invasive candidiasis in the elderly: A review. Clin. Interv. Aging 2013, 8, 1199-1208. [CrossRef] [PubMed]

24. Dimopoulos, G.; Paiva, J.-A.; Meersseman, W.; Pachl, J.; Grigoras, I.; Sganga, G.; Montravers, P.; Auzinger, G.; Sá, M.B.; Miller, P.J.; et al. Efficacy and safety of anidulafungin in elderly, critically ill patients with invasive Candida infections: A post hoc analysis. Int. J. Antimicrob. Agents 2012, 40, 521-526. [CrossRef] [PubMed]

25. Muñoz, P.; Giannella, M.; Fanciulli, C.; Guinea, J.; Valerio, M.; Rojas, L.; Rodríguez-Créixems, M.; Bouza, E. Candida tropicalis fungaemia: Incidence, risk factors and mortality in a general hospital. Clin. Microbiol. Infect. 2011, 17, 1538-1545. [CrossRef]

26. Leroy, O.; Gangneux, J.-P.; Montravers, P.; Mira, J.-P.; Gouin, F.; Sollet, J.-P.; Carlet, J.; Reynes, J.; Rosenheim, M.; Regnier, B.; et al. Epidemiology, management, and risk factors for death of invasive Candida infections in critical care: A multicenter, prospective, observational study in France (2005-2006). Crit. Care Med. 2009, 37, 1612-1618. [CrossRef]

27. Deorukhkar, S.C.; Saini, S.; Mathew, S. Virulence factors contributing to pathogenicity of Candida tropicalis and its antifungal susceptibility profile. Int. J. Microbiol. 2014, 2014, 456878. [CrossRef]

28. Gupta, A.; Gupta, A.; Varma, A. Candida glabrata candidemia: An emerging threat in critically ill patients. Indian J. Crit. Care Med. 2015, 19, 151-154. [CrossRef] [PubMed]

29. Baronia, A.K.; Ahmed, A. Comments on "Candida glabrata candidemia, an emerging threat in critically ill patients". Indian J. Crit. Care Med. 2015, 19, 294-295. [CrossRef]

30. Hedderwick, S.A.; Wan, J.Y.; Bradley, S.F.; Sangeorzan, J.A.; Terpenning, M.S.; Kauffman, C.A. Risk Factors for Colonization with Yeast Species in a Veterans Affairs Long-term Care Facility. J. Am. Geriatr. Soc. 1998, 46, 849-853. [CrossRef]

31. Pappas, P.G.; Rex, J.; Lee, J.; Hamill, R.J.; Larsen, R.A.; Powderly, W.; Kauffman, C.A.; Hyslop, N.; Mangino, J.E.; Chapman, S.; et al. A Prospective Observational Study of Candidemia: Epidemiology, Therapy, and Influences on Mortality in Hospitalized Adult and Pediatric Patients. Clin. Infect. Dis. 2003, 37, 634-643. [CrossRef]

32. Tan, T.Y.; Hsu, L.Y.; Alejandria, M.M.; Chaiwarith, R.; Chinniah, T.; Chayakulkeeree, M.; Choudhury, S.; Chen, Y.H.; Shin, J.H.; Kiratisin, K.; et al. Antifungal susceptibility of invasive Candida bloodstream isolates from the Asia-Pacific region. Med. Mycol. 2016, 54, 471-477. [CrossRef] [PubMed]

33. Metin, D.Y.; Hilmioglu-Polat, S.; Samlioglu, P.; Doganay-Oflazoglu, B.; Inci, R.; Tumbay, E. Evaluation of Antifungal Susceptibility Testing with Microdilution and Etest Methods of Candida Blood Isolates. Mycopathologia 2011, 172, 187-199. [CrossRef] [PubMed]

34. Taj-Aldeen, S.J.; Kolecka, A.; Boesten, R.; Alolaqi, A.; Almaslamani, M.; Chandra, P.; Meis, J.F.; Boekhout, T. Epidemiology of candidemia in Qatar, the Middle East: Performance of MALDI-TOF MS for the identification of Candida species, species distribution, outcome, and susceptibility pattern. Infection 2013, 42, 393-404. [CrossRef] [PubMed]

35. Silva, A.P.; Miranda, I.; Lisboa, C.; Pina-Vaz, C.; Rodrigues, A.G. Prevalence, Distribution, and Antifungal Susceptibility Profiles of Candida parapsilosis, C. orthopsilosis, and C. metapsilosis in a Tertiary Care Hospital. J. Clin. Microbiol. 2009, 47, $2392-2397$. [CrossRef]

36. Miyazaki, H.; Miyazaki, Y.; Geber, A.; Parkinson, T.; Hitchcock, C.; Falconer, D.J.; DWard, D.J.; Marsden, K.; Bennett, J.B. Fluconazole resistance associated with drug efflux and increased transcription of a drug transporter gene, PDH1, in Candida glabrata. Antimicrob. Agents Chemother. 1998, 42, 1695-1701. [CrossRef]

37. Barchiesi, F.; Di Francesco, L.F.; Arzeni, D.; Caselli, F.; Gallo, D.; Scalise, G. Electrophoretic karyotyping and triazole susceptibility of Candida glabrata clinical isolates. Eur. J. Clin. Microbiol. Infect. Dis. 1999, 18, 184-187. [CrossRef]

38. You, L.; Qian, W.; Yang, Q.; Mao, L.; Zhu, L.; Huang, X.; Jin, J.; Meng, H. Affiliations expand ERG11 gene mutations and MDR1 upregulation confer pan-azole resistance in Candida tropicalis causing disseminated candidiasis in an acute lymphoblastic leukemia patient on posaconazole prophylaxis. Antimicrob. Agents Chemother. 2017, 61, e02496-16. [CrossRef]

39. Jin, L.; Cao, Z.; Wang, Q.; Wang, Y.; Wang, X.; Chen, H.; Wang, H. MDR1 overexpression combined with ERG11 mutations induce high-level fluconazole resistance in Candida tropicalis clinical isolates. BMC Infect. Dis. 2018, 18, 162. [CrossRef]

40. Oxman, D.A.; Chow, J.K.; Frendl, G.; Hadley, S.; Hershkovitz, S.; Ireland, P.; McDermott, L.A.; Tsai, K.; Marty, F.; Kontoyiannis, D.P.; et al. Candidaemia associated with decreased in vitro fluconazole susceptibility: Is Candida speciation predictive of the susceptibility pattern? J. Antimicrob. Chemother. 2010, 65, 1460-1465. [CrossRef] 
41. Pfaller, M.A.; Jones, R.N.; Castanheira, M. Regional data analysis of Candida non-albicans strains collected in United States medical sites over a 6-year period, 2006-2011. Mycoses 2014, 57, 602-611. [CrossRef]

42. Tortorano, A.M.; Prigitano, A.; Lazzarini, C.; Passera, M.; Deiana, M.L.; Cavinato, S.; De Luca, C.; Grancini, A.; Cascio, G.L.; Ossi, C.; et al. A 1-year prospective survey of candidemia in Italy and changing epidemiology over one decade. Infection 2013, 41, 655-662. [CrossRef]

43. Faria-Ramos, I.; Neves-Maia, J.; Ricardo, E.; Santos-Antunes, J.; Silva, A.T.; Costa-De-Oliveira, S.; Cantón, E.; Rodrigues, A.G.; Pina-Vaz, C. Species distribution and in vitro antifungal susceptibility profiles of yeast isolates from invasive infections during a Portuguese multicenter survey. Eur. J. Clin. Microbiol. Infect. Dis. 2014, 33, 2241-2247. [CrossRef]

44. Guinea, J.; Zaragoza, O.; Escribano, P.; Mazuelos, E.M.; Pemán, J.; Sanchez-Reus, F.; Cuenca-Estrella, M. Molecular Identification and Antifungal Susceptibility of Yeast Isolates Causing Fungemia Collected in a Population-Based Study in Spain in 2010 and 2011. Antimicrob. Agents Chemother. 2013, 58, 1529-1537. [CrossRef]

45. Wiederhold, N.P. Echinocandin Resistance in Candida Species: A Review of Recent Developments. Curr. Infect. Dis. Rep. 2016, 18, 42. [CrossRef] [PubMed]

46. Chou, H.-H.; Lo, H.-J.; Chen, K.-W.; Liao, M.-H.; Li, S.-Y. Multilocus sequence typing of Candida tropicalis shows clonal cluster enriched in isolates with resistance or trailing growth of fluconazole. Diagn. Microbiol. Infect. Dis. 2007, 58, 427-433. [CrossRef]

47. Wang, Q.; Li, C.; Tang, D.; Tang, K. Molecular epidemiology of Candida tropicalis isolated from urogenital tract infections. MicrobiologyOpen 2020, 9, 1121. [CrossRef]

48. Fan, X.; Xiao, M.; Liao, K.; Kudinha, T.; Wang, H.; Zhang, L.; Hou, X.; Kong, F.; Xu, Y.-C. Notable Increasing Trend in Azole Non-susceptible Candida tropicalis Causing Invasive Candidiasis in China (August 2009 to July 2014): Molecular Epidemiology and Clinical Azole Consumption. Front. Microbiol. 2017, 8, 464. [CrossRef] [PubMed]

49. Lyon, G.M.; Karatela, S.; Sunay, S.; Adiri, Y. Antifungal Susceptibility Testing of Candida Isolates from the Candida Surveillance Study. J. Clin. Microbiol. 2010, 48, 1270-1275. [CrossRef]

50. Odds, F.C.; Bougnoux, M.-E.; Shaw, D.J.; Bain, J.M.; Davidson, A.D.; Diogo, D.; Jacobsen, M.D.; Lecomte, M.; Li, S.-Y.; Tavanti, A.; et al. Molecular Phylogenetics of Candida albicans. Eukaryot. Cell 2007, 6, 1041-1052. [CrossRef]

51. Shin, J.H.; Bougnoux, M.-E.; D’Enfert, C.; Kim, S.H.; Moon, C.-J.; Joo, M.Y.; Lee, K.; Kim, M.-N.; Lee, H.S.; Shin, M.G.; et al. Genetic Diversity among Korean Candida albicans Bloodstream Isolates: Assessment by Multilocus Sequence Typing and Restriction Endonuclease Analysis of Genomic DNA by Use of BssHII. J. Clin. Microbiol. 2011, 49, 2572-2577. [CrossRef]

52. Ropars, J.; Maufrais, C.; Diogo, D.; Marcet-Houben, M.; Perin, A.; Sertour, N.; Mosca, K.; Permal, E.; Laval, G.; Bouchier, C.; et al. Gene flow contributes to diversification of the major fungal pathogen Candida albicans. Nat. Commun. 2018, 9, 2253. [CrossRef] [PubMed]

53. Smith, A.C.; Hickma, M.A. Host-induced genome instability rapidly generates phenotypic variation across Candida albicans strains and ploidy states. mSphere 2020, 5, e00433-20. [CrossRef] [PubMed]

54. Odds, F.C. Molecular phylogenetics and epidemiology of Candida albicans. Futur. Microbiol. 2010, 5, 67-79. [CrossRef]

55. Pham, L.; Pharkjaksu, S.; Chongtrakool, P.; Suwannakarn, K.; Ngamskulrungroj, P. A Predominance of Clade 17 Candida albicans Isolated from Hemocultures in a Tertiary Care Hospital in Thailand. Front. Microbiol. 2019, 10, 1194. [CrossRef]

56. Furlaneto, M.C.; Goes, H.P.; Perini, H.F.; Dos Santos, R.C.; Furlaneto-Maia, L. How much do we know about hemolytic capability of pathogenic Candida species? Folia Microbiol. 2018, 63, 405-412. [CrossRef]

57. Hou, X.; Xiao, M.; Chen, S.C.; Kong, F.; Wang, H.; Chu, Y.Z.; Kang, M.; Sun, Z.Y.; Zhi-Hu, H.; Li, R.Y.; et al. Molecular epidemiology and antifungal susceptibility of Candida glabrata in China (August 2009 to July 2014): A multi-center study. Front. Microbiol. 2017, 8, 880. [CrossRef]

58. Byun, S.A.; Won, E.J.; Kim, M.-N.; Lee, W.G.; Lee, K.; Lee, H.S.; Uh, Y.; Healey, K.; Perlin, D.S.; Choi, M.J.; et al. Multilocus Sequence Typing (MLST) Genotypes of Candida glabrata Bloodstream Isolates in Korea: Association with Antifungal Resistance, Mutations in Mismatch Repair Gene (Msh2), and Clinical Outcomes. Front. Microbiol. 2018, 9, 1523. [CrossRef] [PubMed]

59. Carreté, L.; Ksiezopolska, E.; Pegueroles, C.; Gómez-Molero, E.; Saus, E.; Iraola-Guzmán, S.; Loska, D.; Bader, O.; Fairhead, C.; Gabaldón, T. Patterns of Genomic Variation in the Opportunistic Pathogen Candida glabrata Suggest the Existence of Mating and a Secondary Association with Humans. Curr. Biol. 2018, 28, 15-27.e7. [CrossRef]

60. Amanloo, S.; Shams-Ghahfarokhi, P.M.; Ghahri, M.; Razzaghi-Abyaneh, M. Genotyping of clinical isolates of Candida glabrata from Iran by multilocus sequence typing and determination of population structure and drug resistance profile. Med. Mycol. 2017, 56, 207-215. [CrossRef] 